\title{
A panel of four genes accurately differentiates benign from malignant thyroid nodules
}

\author{
Qing-Xuan Wang ${ }^{1 \dagger}$, En-Dong Chen ${ }^{1 \dagger}$, Ye-Feng Cai ${ }^{1 \dagger}$, Quan $\mathrm{Li}^{1}$, Yi-Xiang Jin ${ }^{1}$, Wen-Xu Jin ${ }^{1}$, Ying-Hao Wang ${ }^{1}$, \\ Zhou-Ci Zheng ${ }^{1}$, Lu Xue ${ }^{2}$, Ou-Chen Wang ${ }^{1}$ and Xiao-Hua Zhang ${ }^{1 *}$
}

\begin{abstract}
Background: Clinicians are confronted with an increasing number of patients with thyroid nodules. Reliable preoperative diagnosis of thyroid nodules remains a challenge because of inconclusive cytological examination of fine-needle aspiration biopsies. Although molecular analysis of thyroid tissue has shown promise as a diagnostic tool in recent years, it has not been successfully applied in routine clinical use, particularly in Chinese patients.

Methods: Whole-transcriptome sequencing of 19 primary papillary thyroid cancer (PTC) samples and matched adjacent normal thyroid tissue (NT) samples were performed. Bioinformatics analysis was carried out to identify candidate diagnostic genes. Then, RT-qPCR was performed to evaluate these candidate genes, and four genes were finally selected. Based on these four genes, diagnostic algorithm was developed (training set: 100 thyroid cancer (TC) and 65 benign thyroid lesions (BTL)) and validated (independent set: 123 TC and 81 BTL) using the support vector machine (SVM) approach.

Results: We discovered four genes, namely fibronectin 1 (FN1), gamma-aminobutyric acid type A receptor beta 2 subunit (GABRB2), neuronal guanine nucleotide exchange factor (NGEF) and high-mobility group AT-hook 2 (HMGA2). A SVM model with these four genes performed with $97.0 \%$ sensitivity, $93.8 \%$ specificity, $96.0 \%$ positive predictive value (PPV), and $95.3 \%$ negative predictive value (NPV) in training set. For additional independent validation, it also showed good performance (92.7\% sensitivity, $90.1 \%$ specificity, $93.4 \%$ PPV, and $89.0 \%$ NPV).
\end{abstract}

Conclusions: Our diagnostic panel can accurately distinguish benign from malignant thyroid nodules using a simple and affordable method, which may have daily clinical application in the near future.

Keywords: Thyroid nodules, Diagnostic panel, Biomarkers

\section{Background}

Thyroid cancer (TC) is the most common endocrine malignancy [1]. Recently, the number of thyroid carcinoma cases annually had increased by $4 \%$ globally [2] and became the fastest growing type of cancer in many countries $[1,3]$. China also suffers a large burden from thyroid cancer $[4,5]$. China accounts for a large portion of thyroid cancer patients around the world. Papillary thyroid cancer (PTC) accounts for $80-85 \%$ of all types of thyroid carcinomas [6].

\footnotetext{
* Correspondence: zxhoncology@sina.com

${ }^{\dagger}$ Equal contributors

${ }^{1}$ Department of Oncology, The First Affiliated Hospital of Wenzhou Medical

University, Wenzhou, Zhejiang Province 325000, China

Full list of author information is available at the end of the article
}

As a result of the increased frequency of medical examinations, such as ultrasonic examination, clinicians are confronted with an increasing number of patients with thyroid nodules. However, the majority of these thyroid nodules are benign, and only a few cases are malignant $[7,8]$. Therefore, accurately diagnosing thyroid nodules preoperatively is important for patients with thyroid cancer to receive timely treatment appropriately. Also, those with benign thyroid nodules can avoid unnecessary treatments, such as diagnostic surgery. Preoperative diagnosis of thyroid nodules can also help to reduce medical burden of patients and the government to a large extent, particularly in developing countries. 
Cytological examination by ultrasound-guided fineneedle aspiration biopsy (US-FNAB) is the most accurate and gold-standard preoperative diagnostic method currently $[9,10]$. However, about $17 \%(10-26 \%)$ of FNAB are reported as indeterminate, and $6 \%(1-11 \%)$ were nondiagnostic; while $72 \%$ median (range $62-85 \%$ ) of undertaken FNAB were benign, and $5 \%(1-8 \%)$ were malignant [11]. As a consequence, most of these patients with indeterminate result undergo unnecessary diagnostic surgery, making them suffer from lifelong replacement therapy of thyroid hormones and corresponding surgical complications [12].

In recent years, molecular analysis of thyroid tissue has shown promise as a diagnostic tool $[8,13-15]$. A microarray-based test, combining the expression levels of 167 genes (The Afirma) can diagnose thyroid nodules with $92 \%$ sensitivity and $52 \%$ specificity [13]. Another panel, named ThyroSeq v2 assay, which consists of more than 50 gene mutations and gene fusions (more than 1,000 hotspots), makes accurate diagnosis with $90 \%$ sensitivity, $93 \%$ specificity, $83 \%$ positive predictive value (PPV), and $96 \%$ negative predictive value (NPV) by using next-generation sequence [8]. Other studies also performed with impressive PPV or NPV [14-17]. Nevertheless, studies aforementioned have their limitations. Some studies contain large amounts of gene alterations, such as The Afirma and ThyroSeq v2 assay, which are expensive and difficult to promote, particularly in lessdeveloped countries. Some studies failed to show both optimal sensitivity and specificity in validation analysis. Moreover, majority of these panels were based on patients from Western countries. Since genetic background is different between Asians and Western populations, whether these panels could be successfully applied to Chinese patients still remain unknown.

Therefore, in the present study, we performed wholetranscriptome sequencing of 19 paired-PTC tissue samples and bioinformatics analysis to investigate global mRNA expression. By using molecular approaches and statistical models, we successfully established a diagnosis model that combines only four genes: fibronectin 1 (FN1), gamma-aminobutyric acid type A receptor beta 2 subunit (GABRB2), neuronal guanine nucleotide exchange factor (NGEF), and high-mobility group AT-hook 2 (HMGA2). This diagnosis model could discriminate malignant from benign thyroid nodules with both high sensitivity and specificity in Chinese patients.

\section{Methods}

Next generation sequencing and bioinformatics analysis

Total RNA was extracted from tissue samples using TRIZOL Reagent (Invitrogen) according to the manufacturer's protocol. After the quality test, The cDNA libraries were prepared using Ion Total RNA-Seq Kit v2.0 (Life
Technologies) according to the manufacturer's instructions. The cDNA libraries were then processed for sequencing using Illumina Hiseq 2500 according to the commercially available protocols. Before reads mapping, clean reads were obtained from the raw reads by removing the adaptor sequences, reads with $>5 \%$ ambiguous bases, and lowquality reads. The clean reads were then aligned to the human genome (version: GRCH37) using the MapSplice program (v2.1.6, University of Kentucky, Lexington, KY, USA). We applied Ebseq algorithm to screen out the differently expressed genes using the following criteria: 1) fold change (FC) $>2$ for up or downregulation; 2) false discovery rate $(\mathrm{FDR})<0.05$ and 3$) P$-Value $<0.05$.

\section{Patients and tissue collection}

Primary TC samples or benign thyroid lesions and their matched adjacent normal thyroid tissue samples were obtained at the time of initial surgery from the First Affiliated Hospital of Wenzhou Medical University. Inclusion and exclusion criteria are as follows, inclusion criteria: patients with surgical indication; tumor size larger than $5 \mathrm{~mm}$; papillary thyroid cancer or follicular thyroid cancer or anaplastic thyroid cancer or medullary thyroid cancer or benign thyroid lesions; with accurate postoperative pathological diagnosis; with informed consent from patients. Exclusion criteria: tumor size less than or equal to $5 \mathrm{~mm}$; with inconclusive postoperative pathological diagnosis; with other malignant tumors; patients with surgical contraindications. Samples were snapfrozen in liquid nitrogen immediately after surgical resection and subsequently stored at a $-80{ }^{\circ} \mathrm{C}$ freezer. All the training and validation samples set used in this study are snap frozen tissues. Histopathological slides were reviewed retrospectively for all cases to confirm the histological diagnosis and to ensure abundant cancer content of the tumor by two pathologists. Detailed information about these patients are shown in Additional files 1 and 2. Informed consent for the scientific use of biological material was obtained from each patient and the work was approved by the Ethics Committee of the First Affiliated Hospital of Wenzhou Medical University.

\section{RNA isolation and RT-qPCR}

Total RNA was isolated using TRIZOL Reagent (Invitrogen) and reverse transcription (TOYOBO, Japan) was performed according to the manufacturer's instructions. Quantitative real-time PCR (RT-qPCR) analysis was performed in triplicate on the ABI prism 7500 sequence detection system (Applied Biosystems, USA) using the THUNDERBIRD SYBR qPCR Mix (TOYOBO, Japan) according to manufacturer's instructions. The GAPDH mRNA level was used for normalization. Primer sequences were as follows: FN1: 5' TGGCCCCCACCTTCTTG -3' (forward) and 5' - TGCGG GAAAAATCCCTTCTA -3' (reverse); GABRB2: 5' - ACT 
GCCGTGTCACATCCTCTAA -3' (forward) and 5' - TGG AACTGTCAACTTGCTTCAAA -3' (reverse); NGEF: 5' GAGCTGGAAATGGTGGTGAAG -3' (forward) and 5' - TTCCGTGCGGCTCATTTT -3' (reverse); HMG A2: 5' - GACCCAAAGGCAGCAAAAAC -3' (forward) and 5 ' - AGTGGCTTCTGCTTTCTTTTGAG -3'(reverse); GAPDH: 5'-GGTCGGAGTCAACGGATTTG-3'(forward) and 5'-ATGAGCCCCAGCCTTCTCCAT -3'(reverse).

\section{Model development}

We evaluated several methodologies for building statistical models that can predict benign versus malignant thyroid nodules based on expression level of the four genes. Finally, the SVM (support vector machine) was used for classification. With the modeling platform of MATLAB 2014a, we establish the SVM model for the classification of benign and malignant thyroid nodules by using Libsvm 3.20. During the development of SVM model, using the training data, we chose the C-SVC and RBF kernel functions and used the grid search method to debug the model. The grid c bound was -8 to 8 , the grid c step was 0.5 , the grid g bound was -8 to 8 , and the grid g step was 0.5 . The fold number of cross validation was 5 .

$$
\text { Plabel }=\operatorname{sgn}(\Sigma \mathrm{ni}=0 \text { wi } \exp (- \text { gamma }|(x i-x)| 2+b))
$$

\section{Statistical analysis}

Data on normal distribution were expressed as mean \pm standard variation (SD) and were compared with t-test. Categorical variables were expressed as percentage and were compared with Chi-square test or Fisher's exact test, as appropriate. All $P$ values were two sided, and a $P$ value of $<0.05$ was considered statistically significant. Statistical analysis was performed with SPSS software version 19.0 (SPSS, Chicago, IL, USA). GraphPad Prism 5 (GraphPad Software, USA) was used for graphs.

\section{Results}

Filtrating differentially-expressed genes in TC by wholetranscriptome sequence

We performed whole-transcriptome sequencing of 19 paired-PTC tissue samples to filtrate differentiallyexpressed genes. We identified a total of 212 differentiallyexpressed genes from the 19 paired-PTC tissue samples $\left(\log _{2}\right.$ FC $>1.0$, FDR $<0.05$ and $P$-Value $\left.<0.05\right)$ (Fig. 1), including 99 overexpressed and 113 downregulated genes,

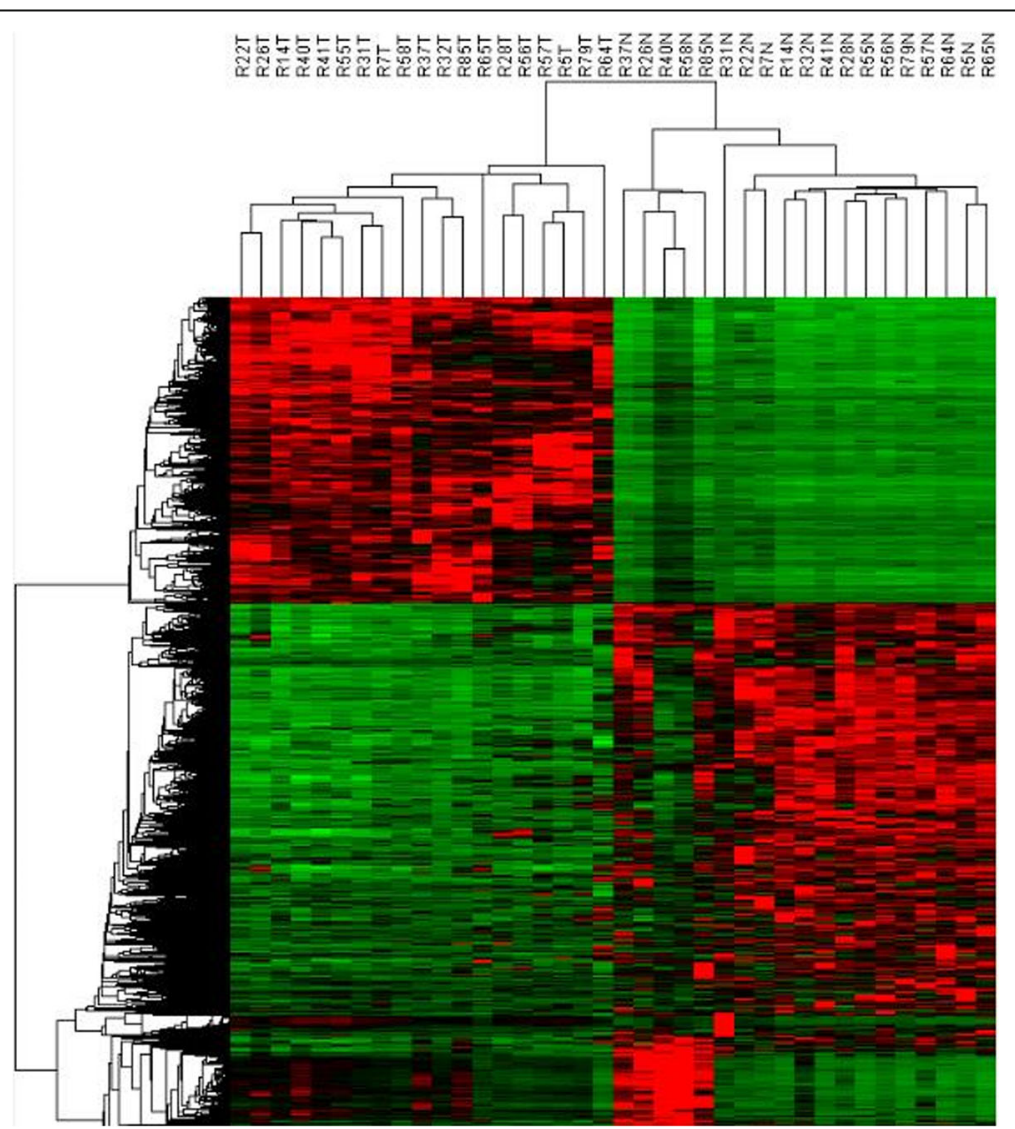

Fig. 1 Differentially expressed mRNAs in PTC tissue samples and adjacent normal tissue samples are analyzed using hierarchical clustering. Each row represents a single mRNA and each column represents one tissue sample. Red indicates high relative expression and green indicates low relative expression 
and then the 99 overexpressed genes were given focus. We raised the FC cut-off value to a higher level $\left(\log _{2} \mathrm{FC}>4.0\right)$ to obtain more limited genes, which are significantly overexpressed. Only 33 overexpressed genes were identified. To obtain genes that are highly associated with thyroid tumor, we screened out the intersection of these 33 overexpressed genes and adenocarcinoma related genes, including only 12 genes (Fig. 2). Then, we investigated the expression of these 12 overexpressed genes in our 19 paired PTC samples with sequencing data (19 PTC and 19 NT). As shown in Fig. 2, all 12 genes showed significant differential expression between TC and NT, with FN1, GABRB2, NGEF and HMGA2 showing the best diagnostic value. Finally, these four genes with the most diagnostic value were filtrated. The flowchart of our study design is presented in Fig. 3.

\section{Training set: establishing the diagnostic panel}

To establish diagnostic panel, mRNA expression levels of the four genes were assessed in 165 samples (100 TC and 65 BTL) using RT-qPCR. Result of each gene is shown in Fig. 4a. Each of four genes demonstrated decent ability to differentiate malignancy and benignity. Using SVM statistical model, we successfully established diagnostic panel that combines the four genes (FN1,
GABRB2, NGEF and HMGA2). Results revealed that the panel was able to differentiate thyroid nodules excellently. $95.8 \%$ (158/165 samples correctly classified) of the samples were correctly classified (Sensibility: $97.0 \%$, Specificity: 93.8 \%, PPV: 96.0 \%, NPV: $95.3 \%$ ).

\section{Validation set: validating the panel in external independent samples}

To validate panel performance, mRNA expression levels of the four genes were measured by RT-qPCR in another 204 samples (123 TC and $81 \mathrm{BTL}$ ). Similar to previous data, relative expression level of the four genes were significantly upregulated (Fig. 4b). The panel also achieved high accuracy in validation set, with $91.7 \%$ accuracy (187/204 samples correctly classified). Only nine malignant thyroid tumors $(4.4 \%)$ and 8 benign thyroid lesions (3.9\%) were misclassified among all the 204 samples. Panel performance based on RT-qPCR was satisfactory, with $91.7 \%$ sensitivity, $92.7 \%$ sensitivity, $90.1 \%$ specificity, 93.4 \% PPV and 89.0 \% NPV.

\section{Discussion}

Thyroid cancer, particularly PTC, has become the fastest growing type of cancer in recent years $[1,3]$. Owing to the
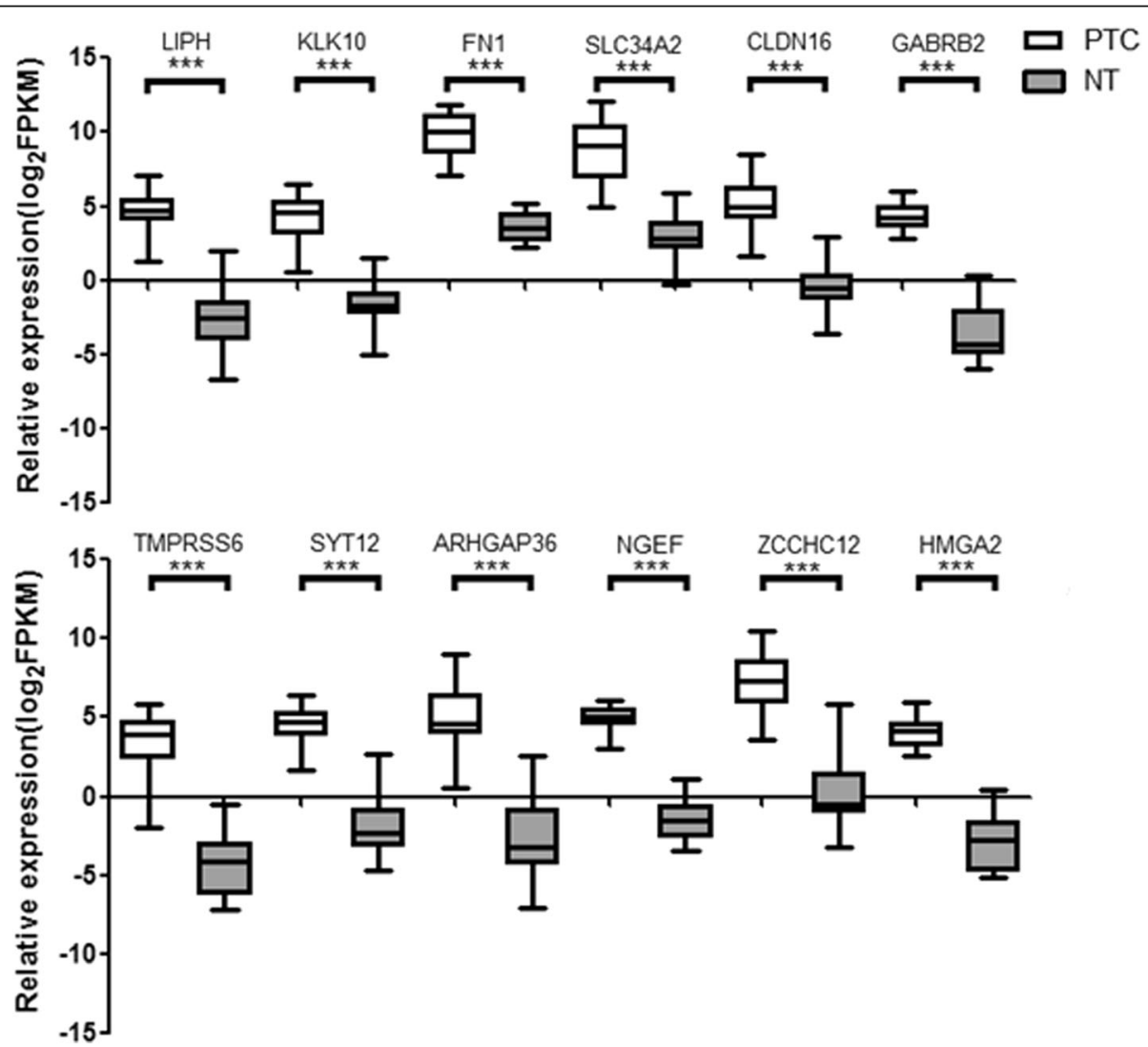

Fig. 2 Expression of the 12 overexpressed genes in our sequencing data (19 PTC and 19 NT). ${ }^{* * P}<0.05 ;{ }^{* *} P<0.001$ 


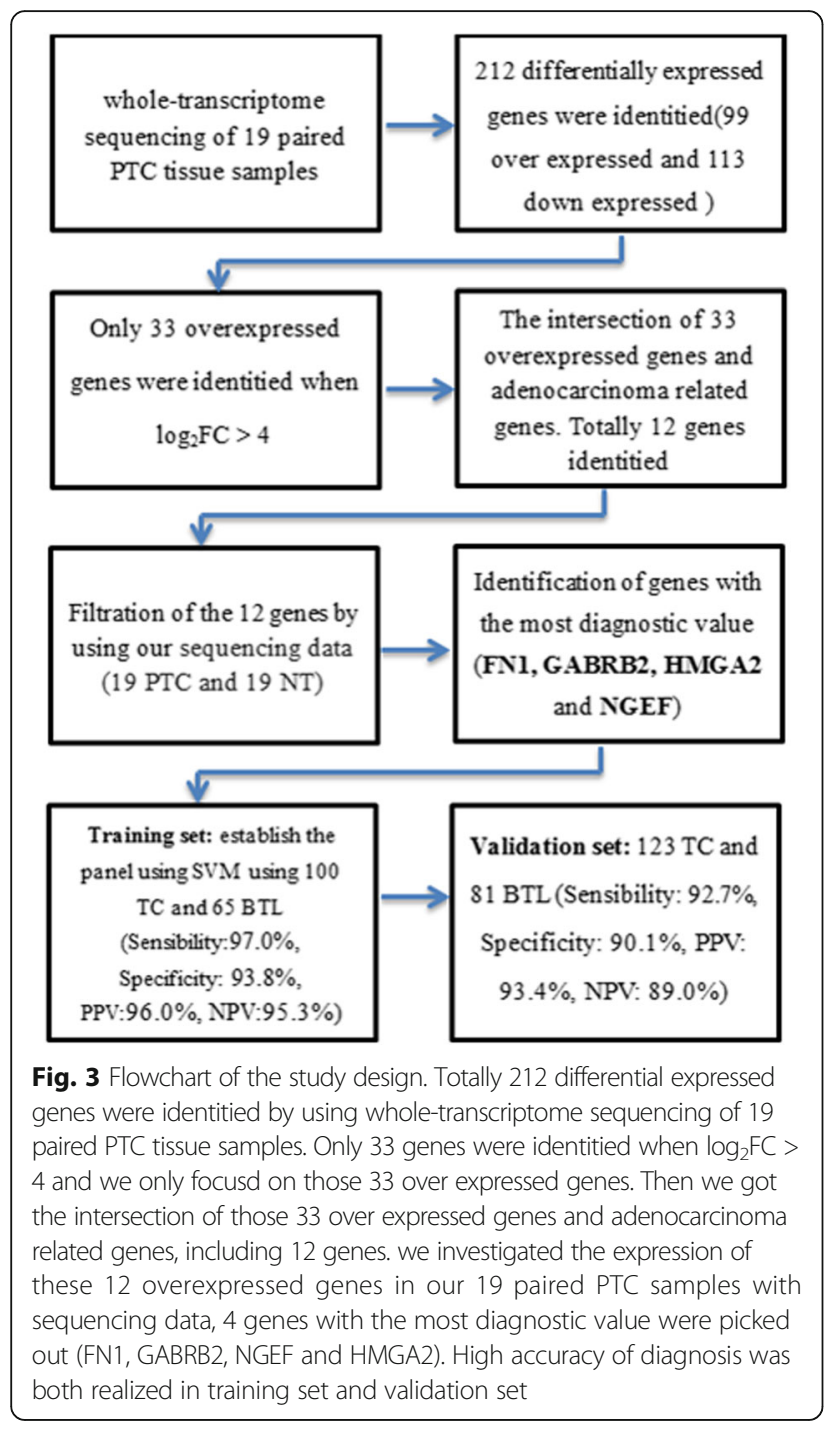

frequency of medical examinations, clinicians are now faced with an even increasing number of patients with thyroid nodules, most of which, however, are benign $[7,8]$. Avoiding unnecessary surgery, especially total thyroidectomies, thereby reducing surgery-associated risks and subsequent treatments, is still an intractable challenge for clinicians. Thus, accurately distinguishing benign from malignant thyroid nodules preoperatively is important.

Considering this challenge, previous studies have developed several diagnostic panels through high-throughput technologies, like next-generation sequence and microarray $[8,13-15,18,19]$. A prospective study evaluated diagnostic molecular test consisting of 167 genes in indeterminate nodules, which presented high sensitivity (92\%), but low specificity (52\%) [13]. Some additional research reports consistent results in using the classifier [20, 21], while some reported only $17 \%$ malignancy rate confirmation in indeterminate nodules [22]. Moreover, the test is not cost-effective outside of North America [20]. Another panel, named ThyroSeq v2 assay, which consists of more than 50 gene mutations and gene fusions (more than 1,000 hotspots), performed with $90 \%$ sensitivity, $93 \%$ specificity, $83 \%$ PPV, and $96 \%$ NPV by using next-generation sequence [8]. Other studies also achieved encouraging effects [14-19]. However, these diagnostic panels are too complex and costly to apply in clinical practice. Also, they have not yet been proven to be effective in Asian population. Many studies have shown that genetic background is different between Asians and Western populations. For example, a gene expression classifier (Afirma) showed distinctly different sensitivity and specificity in different populations partly because of different genetic background [13, 20, 22-25]. What is more, Xing $M$ et al. reported BRAF mutation occurred in about $45 \%$ of PTC patients in the USA [26] while the rate reported in Asian was much higher, $63.7 \%$ in the study from Jin L et al. [27] and $58 \%$ in the study from Lee JH [28]. However, the rate of TERT promoter mutation was much higher in Western populations than Asian population (about $10 \%$ vs $4.1 \%$ ) [27, 29]. Moreover, the incidence of thyroid cancer is also different between Asians and Western populations [3, 4].

In the present study, we developed a panel that presents excellent performance in discriminating benign from malignant thyroid nodules by combining only four genes (FN1, GABRB2, NGEF and HMGA2). Its performance was further validated by independent external samples. To further confirm its performance in FNAB samples, we also tested the panel in 20 FNAB samples with indeterminate result, which correctly recognized 17 of 20 with $85 \%$ prediction accuracy. In spite of the limited sample size, the panel also showed good discriminating ability in FNAB samples.

FN1 encodes fibronectin involved in cell adhesion and migration processes, including embryogenesis, wound healing, blood coagulation, host defense and metastasis. This gene was reported to be differentially expressed in human cancers [30]. Some research showed that FN1 could help distinguish benign from malignant thyroid tumors [31, 32], which is consistent with our findings.

GABRB2 encodes gamma-aminobutyric acid A receptor, beta 2 subunit. This gene was found to be related to mental diseases, like schizophrenia [33, 34]. A recent study revealed that GABRB2 is highly upregulated in thyroid cancer [35]. In our study, GABRB2 was one of the most significant upregulated genes in 203 differential expression genes.

NGEF has been found to be associated with myopia and obesity-related diseases [36, 37]. However, it is not yet well studied in human cancer. A study from Korea had demonstrated that NGEF is a differentially-expressed gene in PTC [38]. We also found that NGEF is upregulated and can be used for diagnosis. 


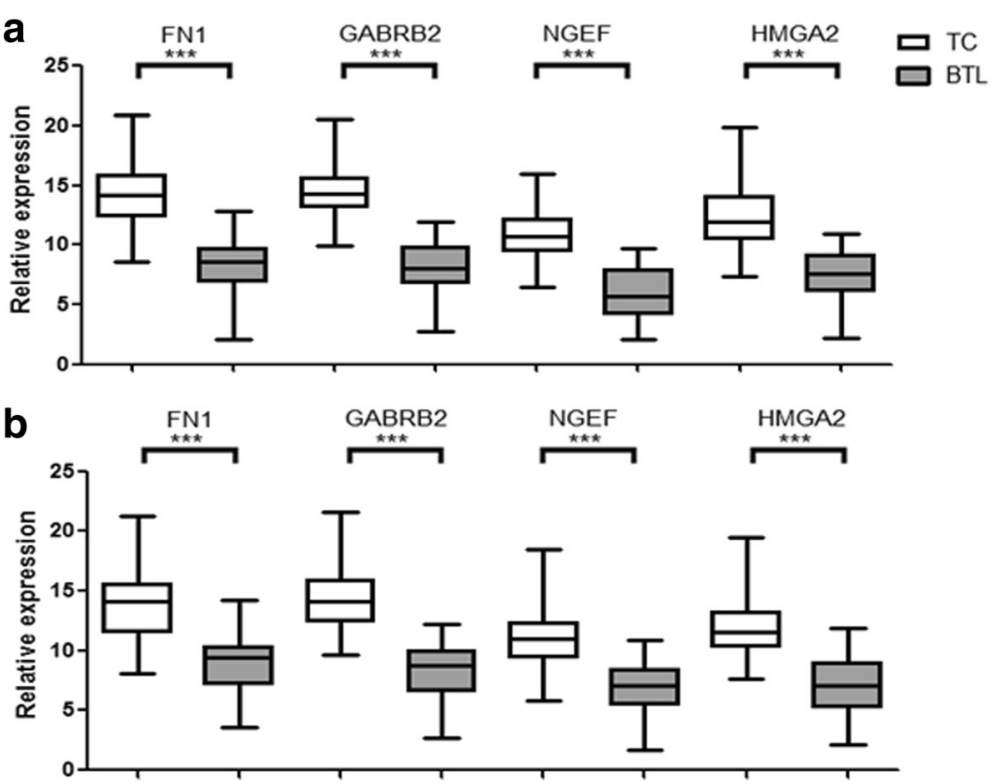

Fig. 4 RT-qPCR analysis of the four genes. a. RT-gPCR analysis of the four genes in training set (100 TC and 65 BTL). b. RT-gPCR analysis of the four genes in validation set (123 TC and $81 \mathrm{BTL}) .{ }^{* *} P<0.05 ;{ }^{* * *} P<0.001$

HMGA2 encodes protein that belongs to non-histone chromosomal high mobility group (HMG) protein family. This protein contains structural DNA-binding domains and may act as a transcriptional regulating factor. Many studies have confirmed that HMGA2 is important in tumorigenesis and tumor progression [39-43], including thyroid cancer $[35,44]$. Chiappetta et al. reported that the mRNA expression of HMGA2 is associated with malignant phenotype in human thyroid neoplasias [44]. HMGA2 was also used as a diagnostic marker in previous studies $[14,45]$. In our study, HMGA2 was significantly upregulated in primary $\mathrm{TC}$ tissue, compared with benign and normal thyroid nodules.

Although we had successfully established a diagnostic panel with excellent performance, the current study has several limitations. First, based on frozen tissue samples, our panel was only tested in a small FNAB size, so it needs to be validated in FNAB samples with large-sample size. Second, our study was a single-center study; multi-center prospective studies are needed.

\section{Conclusions}

In summary, this study successfully established a diagnostic panel by using a simple and affordable method, which utilized only four genes with excellent performance in Chinese patients. We believe this panel could form the basis for a robust, practical, and affordable molecular diagnostic tool for clinical use in the near future.

\section{Additional files}

Additional file 1: Table S1. Clinicopathologic characteristics of 223 thyroid cancer patients enrolled in the study. (DOCX $16 \mathrm{~kb}$ )

Additional file 2: Table S2. Clinicopathologic characteristics of 146 benign thyroid lesions patients enrolled in the study. (DOCX $14 \mathrm{~kb}$ )

\section{Abbreviations}

BTL: Benign thyroid lesions; FC: Fold change; FDR: False discovery rate; FN1: Fibronectin 1; GABRB2: Gamma-aminobutyric acid type A receptor beta 2 subunit; HMGA2: High-mobility group AT-hook 2; NGEF: Neuronal guanine nucleotide exchange factor; NPV: Negative predictive value; NT: Normal thyroid tissues; PPV: Positive predictive value; PTC: Papillary thyroid cancer; SVM: Support vector machine; TC: Thyroid cancer; US-FNAB: Ultrasoundguided fine-needle aspiration biopsy

\section{Acknowledgements}

Not applicable.

\section{Funding}

This work was supported by a grant from the National High Technology Research and Development Program of 863 project of China (NO. 2012AA02A210) and Major Science and Technology Projects of Zhejiang Province (2015C03G2090019).

\section{Availability of data and materials Not applicable.}

Authors' contributions

XHZ and OCW contribute to conception and design. QXW, EDC, YFC and LX contribute to data analysis and manuscript writing. QXW, YXJ, WXJ and YHW performed experiments. QL and ZCZ performed data acquisition. All authors reviewed the manuscript and approved the final authorship. QXW, EDC and YFC have contributed equally to this article.

Competing interests

The authors declare that they have no competing interests. 


\section{Consent for publication}

Informed consent for the scientific use of biological material was obtained from each patient.

\section{Ethics approval and consent to participate}

The work was approved by the Ethics Committee of the First Affiliated Hospital of Wenzhou Medical University.

\section{Author details}

'Department of Oncology, The First Affiliated Hospital of Wenzhou Medical University, Wenzhou, Zhejiang Province 325000, China. ${ }^{2}$ Department of Otolaryngology Head and Neck Surgery, Xinhua Hospital, Shanghai Jiaotong University, School of Medicine, Shanghai 200000, China.

Received: 29 July 2016 Accepted: 22 October 2016

Published online: 28 October 2016

\section{References}

1. Rahib L, Smith BD, Aizenberg R, Rosenzweig AB, Fleshman JM, Matrisian LM Projecting cancer incidence and deaths to 2030: the unexpected burden of thyroid, liver, and pancreas cancers in the United States. Cancer Res. 2014:74:2913-21.

2. Chen AY, Jemal A, Ward EM. Increasing incidence of differentiated thyroid cancer in the United States, 1988-2005. Cancer. 2009:115:3801-7.

3. Siegel R, Ma J, Zou Z, Jemal A. Cancer statistics, 2014. CA Cancer J Clin. 2014;64:9-29.

4. Chen W, Zheng R, Baade PD, Zhang S, Zeng H, Bray F, Jemal A, Yu XQ, He J. Cancer statistics in China, 2015. CA Cancer J Clin. 2016;66:115-32.

5. Xie SH, Chen J, Zhang B, Wang F, Li SS, Xie CH, Tse LA, Cheng JQ. Time trends and age-period-cohort analyses on incidence rates of thyroid cancer in Shanghai and Hong Kong. BMC Cancer. 2014;14:975.

6. Xing M. Molecular pathogenesis and mechanisms of thyroid cancer. Nat Rev Cancer. 2013:13:184-99.

7. Gharib H, Papini E, Paschke R, Duick DS, Valcavi R, Hegedus L, Vitti P, Nodules AAETFoT. American Association of Clinical Endocrinologists, Associazione Medici Endocrinologi, and European Thyroid Association Medical guidelines for clinical practice for the diagnosis and management of thyroid nodules: executive summary of recommendations. Endocr Pract. 2010;16:468-75

8. Nikiforov YE, Carty SE, Chiosea SI, Coyne C, Duvvuri U, Ferris RL, Gooding WE, Hodak SP, LeBeau SO, Ohori NP, Seethala RR, Tublin ME, Yip L, Nikiforova MN. Highly accurate diagnosis of cancer in thyroid nodules with follicular neoplasm/suspicious for a follicular neoplasm cytology by ThyroSeq v2 next-generation sequencing assay. Cancer. 2014;120:3627-34.

9. Schneider DF, Chen H. New developments in the diagnosis and treatment of thyroid cancer. CA Cancer J Clin. 2013;63:374-94.

10. Xing M, Haugen BR, Schlumberger M. Progress in molecular-based management of differentiated thyroid cancer. Lancet. 2013;381:1058-69.

11. Wang CC, Friedman L, Kennedy GC, Wang H, Kebebew E, Steward DL, Zeiger MA, Westra WH, Wang Y, Khanafshar E, Fellegara G, Rosai J, Livolsi V, Lanman RB. A large multicenter correlation study of thyroid nodule cytopathology and histopathology. Thyroid. 2011;21:243-51.

12. Hundahl SA, Cady B, Cunningham MP, Mazzaferri E, McKee RF, Rosai J, Shah JP, Fremgen AM, Stewart AK, Holzer S, Hundahl SA, Cady B, Cunningham MP, Mazzaferri E, McKee RF, Rosai J, Shah JP, Fremgen AM, Stewart AK, Holzer S. Initial results from a prospective cohort study of 5583 cases of thyroid carcinoma treated in the united states during 1996. U.S. and German Thyroid Cancer Study Group. An American College of Surgeons Commission on Cancer Patient Care Evaluation study. Cancer. 2000:89:202-17.

13. Alexander EK, Kennedy GC, Baloch ZW, Cibas ES, Chudova D, Diggans J, Friedman L, Kloos RT, LiVolsi VA, Mandel SJ, Raab SS, Rosai J, Steward DL, Walsh PS, Wilde II, Zeiger MA, Lanman RB, Haugen BR. Preoperative diagnosis of benign thyroid nodules with indeterminate cytology. N Engl J Med. 2012:367:705-15.

14. Barros-Filho MC, Marchi FA, Pinto CA, Rogatto SR, Kowalski LP. High Diagnostic Accuracy Based on CLDN10, HMGA2, and LAMB3 Transcripts in Papillary Thyroid Carcinoma. J Clin Endocrinol Metab. 2015;100:E890-9.

15. Keutgen XM, Filicori F, Crowley MJ, Wang Y, Scognamiglio T, Hoda R, Buitrago D, Cooper D, Zeiger MA, Zarnegar R, Elemento O, Fahey 3rd TJ. A panel of four miRNAs accurately differentiates malignant from benign indeterminate thyroid lesions on fine needle aspiration. Clin Cancer Res. 2012;18:2032-8.
16. Cerutti JM, Delcelo R, Amadei MJ, Nakabashi C, Maciel RM, Peterson B, Shoemaker J, Riggins GJ. A preoperative diagnostic test that distinguishes benign from malignant thyroid carcinoma based on gene expression. J Clin Invest. 2004;113:1234-42.

17. Zheng B, Liu J, Gu J, Lu Y, Zhang W, Li M, Lu H. A three-gene panel that distinguishes benign from malignant thyroid nodules. Int J Cancer. 2015;136:1646-54

18. Vriens MR, Weng J, Suh I, Huynh N, Guerrero MA, Shen WT, Duh QY, Clark $\mathrm{OH}$, Kebebew E. MicroRNA expression profiling is a potential diagnostic tool for thyroid cancer. Cancer. 2012;118:3426-32.

19. Liu Y, Cope L, Sun W, Wang Y, Prasad N, Sangenario L, Talbot K, Somervell H, Westra W, Bishop J, Califano J, Zeiger M, Umbricht C. DNA copy number variations characterize benign and malignant thyroid tumors. J Clin Endocrinol Metab. 2013;98:E558-66.

20. Alexander EK, Schorr M, Klopper J, Kim C, Sipos J, Nabhan F, Parker C, Steward DL, Mandel SJ, Haugen BR. Multicenter clinical experience with the Afirma gene expression classifier. J Clin Endocrinol Metab. 2014;99:119-25.

21. Duick DS, Klopper JP, Diggans JC, Friedman L, Kennedy GC, Lanman RB, Mclver B. The impact of benign gene expression classifier test results on the endocrinologist-patient decision to operate on patients with thyroid nodules with indeterminate fine-needle aspiration cytopathology. Thyroid. 2012;22:996-1001.

22. Mclver B, Castro MR, Morris JC, Bernet V, Smallridge R, Henry M, Kosok L, Reddi $\mathrm{H}$. An independent study of a gene expression classifier (Afirma) in the evaluation of cytologically indeterminate thyroid nodules. J Clin Endocrinol Metab. 2014:99:4069-77.

23. Brauner E, Holmes BJ, Krane JF, Nishino M, Zurakowski D, Hennessey JV, Faquin WC, Parangi S. Performance of the Afirma Gene Expression Classifier in Hurthle Cell Thyroid Nodules Differs from Other Indeterminate Thyroid Nodules. Thyroid. 2015;25:789-96.

24. Lastra RR, Pramick MR, Crammer CJ, LiVolsi VA, Baloch ZW. Implications of a suspicious afirma test result in thyroid fine-needle aspiration cytology: an institutional experience. Cancer Cytopathol. 2014;122:737-44.

25. Yang SE, Sullivan PS, Zhang J, Govind R, Levin MR, Rao JY, Moatamed NA. Has Afirma gene expression classifier testing refined the indeterminate thyroid category in cytology? Cancer Cytopathol. 2016;124:100-9.

26. Xing M. BRAF mutation in thyroid cancer. Endocr Relat Cancer. 2005;12:245-62.

27. Jin L, Chen E, Dong S, Cai Y, Zhang X, Zhou Y, Zeng R, Yang F, Pan C, Liu Y, Wu W, Xing M, Zhang $X$, Wang O. BRAF and TERT promoter mutations in the aggressiveness of papillary thyroid carcinoma: a study of 653 patients. Oncotarget. 2016;7:18346-55

28. Lee JH, Lee ES, Kim YS, Won NH, Chae YS. BRAF mutation and AKAPg expression in sporadic papillary thyroid carcinomas. Pathology. 2006;38:201-4.

29. Liu X, Qu S, Liu R, Sheng C, Shi X, Zhu G, Murugan AK, Guan H, Yu H, Wang $Y$, Sun $H$, Shan $Z$, Teng $W$, Xing M. TERT promoter mutations and their association with BRAF V600E mutation and aggressive clinicopathological characteristics of thyroid cancer. J Clin Endocrinol Metab. 2014;99:E1130-6.

30. Helleman J, Jansen MP, Ruigrok-Ritstier K, van Staveren IL, Look MP, Meijer-van Gelder ME, Sieuwerts AM, Klijn JG, Sleijfer S, Foekens JA, Berns EM. Association of an extracellular matrix gene cluster with breast cancer prognosis and endocrine therapy response. Clin Cancer Res. 2008;14:5555-64.

31. Fryknas M, Wickenberg-Bolin U, Goransson H, Gustafsson MG, Foukakis T, Lee JJ, Landegren U, Hoog A, Larsson C, Grimelius L, Wallin G, Pettersson U, Isaksson A. Molecular markers for discrimination of benign and malignant follicular thyroid tumors. Tumour Biol. 2006;27:211-20.

32. da Silveira Mitteldorf CA, de Sousa-Canavez JM, Leite KR, Massumoto C, Camara-Lopes LH. FN1, GALE, MET, and QPCT overexpression in papillary thyroid carcinoma: molecular analysis using frozen tissue and routine fineneedle aspiration biopsy samples. Diagn Cytopathol. 2011;39:556-61.

33. Tsang SY, Zhong S, Mei L, Chen J, Ng SK, Pun FW, Zhao C, Jing B, Chark R, Guo J, Tan Y, Li L, Wang C, Chew SH, Xue H. Social cognitive role of schizophrenia candidate gene GABRB2. PLoS One. 2013;8, e62322.

34. Srivastava S, Cohen J, Pevsner J, Aradhya S, McKnight D, Butler E, Johnston $M$, Fatemi A. A novel variant in GABRB2 associated with intellectual disability and epilepsy. Am J Med Genet A. 2014;164A:2914-21.

35. Wu ZY, Wang SM, Chen ZH, Huv SX, Huang K, Huang BJ, Du JL, Huang CM, Peng L, Jian ZX, Zhao G. MiR-204 regulates HMGA2 expression and inhibits cell proliferation in human thyroid cancer. Cancer Biomark. 2015;15:535-42.

36. Guo L, Frost MR, Siegwart Jr JT, Norton TT. Scleral gene expression during recovery from myopia compared with expression during myopia development in tree shrew. Mol Vis. 2014;20:1643-59. 
37. Kim HJ, Park JH, Lee S, Son HY, Hwang J, Chae J, Yun JM, Kwon H, Kim JI, Cho B. A Common Variant of NGEF Is Associated with Abdominal Visceral Fat in Korean Men. PLoS One. 2015;10, e0137564.

38. Chung KW, Kim SW, Kim SW. Gene expression profiling of papillary thyroid carcinomas in Korean patients by oligonucleotide microarrays. J Korean Surg Soc. 2012;82:271-80.

39. Shi Z, Li X, Wu D, Tang R, Chen R, Xue S, Sun X. Silencing of HMGAZ suppresses cellular proliferation, migration, invasion, and epithelialmesenchymal transition in bladder cancer. Tumour Biol. 2016;37:7515-23.

40. Zhao XP, Zhang H, Jiao JY, Tang DX, Wu YL, Pan CB. Overexpression of HMGA2 promotes tongue cancer metastasis through EMT pathway. J Transl Med. 2016;14:26.

41. D'Armiento J, Shiomi T, Marks S, Geraghty P, Sankarasharma D, Chada K. Mesenchymal Tumorigenesis Driven by TSC2 Haploinsufficiency Requires HMGA2 and Is Independent of mTOR Pathway Activation. Cancer Res. 2016;76:844-54.

42. Kumar MS, Armenteros-Monterroso E, East $\mathrm{P}$, Chakravorty $\mathrm{P}$, Matthews $\mathrm{N}$ Winslow MM, Downward J. HMGA2 functions as a competing endogenous RNA to promote lung cancer progression. Nature. 2014;505:212-7.

43. Natarajan S, Begum F, Gim J, Wark L, Henderson D, Davie JR, HombachKlonisch S, Klonisch T. High Mobility Group A2 protects cancer cells against telomere dysfunction. Oncotarget. 2016;7:12761-82.

44. Chiappetta G, Ferraro A, Vuttariello E, Monaco M, Galdiero F, De Simone V Califano D, Pallante P, Botti G, Pezzullo L, Pierantoni GM, Santoro M, Fusco A. HMGA2 mRNA expression correlates with the malignant phenotype in human thyroid neoplasias. Eur J Cancer. 2008:44:1015-21.

45. Lappinga PJ, Kip NS, Jin L, Lloyd RV, Henry MR, Zhang J, Nassar A. HMGA2 gene expression analysis performed on cytologic smears to distinguish benign from malignant thyroid nodules. Cancer Cytopathol. 2010;1 18:287-97.

Submit your next manuscript to BioMed Central and we will help you at every step:

- We accept pre-submission inquiries

- Our selector tool helps you to find the most relevant journal

- We provide round the clock customer support

- Convenient online submission

- Thorough peer review

- Inclusion in PubMed and all major indexing services

- Maximum visibility for your research

Submit your manuscript at www.biomedcentral.com/submit
Biomed Central 